THE

FEDDRAL

ROSDIRVE

ST.LOUIS

WORKING PAPER SERIES

\title{
Inflation Persistence and Flexible Prices
}

\author{
Robert Dittmar, \\ William T. Gavin \\ and \\ Finn E. Kydland \\ Working Paper 2001-010B \\ http://www.stls.frb.org/research/wp/2001-010.html
}

September 2001

\author{
FEDERAL RESERVE BANK OF ST. LOUIS \\ Research Division \\ 411 Locust Street \\ St. Louis, MO 63102
}

The views expressed are those of the individual authors and do not necessarily reflect official positions of the Federal Reserve Bank of St. Louis, the Federal Reserve System, or the Board of Governors.

Federal Reserve Bank of St. Louis Working Papers are preliminary materials circulated to stimulate discussion and critical comment. References in publications to Federal Reserve Bank of St. Louis Working Papers (other than an acknowledgment that the writer has had access to unpublished material) should be cleared with the author or authors. 


\title{
Inflation Persistence and Flexible Prices
}

Revised: September 2001

\begin{abstract}
The inability of rational expectation models with money supply rules to deliver inflation persistence following a transitory deviation of money growth from trend is due to the rapid adjustment of the price level to expected events. The observation of persistent inflation in macroeconomic data leads many economists to believe that prices adjust sluggishly and/or expectations must not be rational. Inflation persistence in U.S. data can be characterized by a vector autocorrelation function relating inflation and deviations of output from trend. In the vector autocorrelation function both inflation and output are highly persistent and there are significant positive dynamic cross-correlations relating inflation and output. This paper shows that a flexible-price general equilibrium business cycle model with money and a central bank using a Taylor rule can account for these patterns. There are no sticky prices and no liquidity effects. Agents' decisions in a period are taken only after all shocks are observed. The monetary policy rule transforms output persistence into inflation persistence and creates positive cross-correlations between inflation and output.
\end{abstract}

Keywords: Inflation Persistence, Flexible Prices, Taylor Rule

JEL Classification: E31, E32, E42

\author{
Robert Dittmar \\ Mathematician \\ Research Department \\ Federal Reserve Bank \\ of St. Louis \\ P.O. Box 442 \\ St. Louis, MO 63166 \\ (314) 444-8592 \\ dittmar@stls.frb.org
}

\author{
William T. Gavin \\ Vice President \\ Research Department \\ Federal Reserve Bank \\ of St. Louis \\ P.O. Box 442 \\ St. Louis, MO 63166 \\ (314) 444-8578 \\ gavin@stls.frb.org
}

\author{
Finn E. Kydland \\ Professor of Economics \\ Graduate School of \\ Industrial Administration \\ Carnegie Mellon \\ University \\ Pittsburgh, PA 15213 \\ (412) 268-3691 \\ kydland@cmu.edu
}

This paper benefited from comments by Jim Bullard, Charles Carlstrom, Mike Dotsey, Bob Rasche, and participants in seminars at meetings of the Midwest Macroeconomic Association in Atlanta in March 2001 and the Society for Dynamic Economics in Stockholm in June 2001. 


\section{Introduction}

The inability of rational expectation models to deliver inflation persistence following a transitory deviation of money growth from trend is due to the rapid adjustment of the price level to expected events. When there is a change in expected future money growth in flexible price models, the price level immediately jumps to reflect these expectations. A persistent shock will cause a bigger jump in the price level — a one-time jump in the inflation rate, which then returns to its underlying trend. Money growth will be persistent, but the inflation rate will not. An important implication of this price adjustment in rational expectations models is that a central bank cannot make inflation persistent merely by making monetary growth persistent.

Ball (1994) showed that monetary shocks do not cause inflation persistence in models with staggered wage or price contracts. In models with nominal rigidities, a persistent money supply shock causes the price level to adjust as rapidly as institutions allow, thus reflecting the expected total effect of that shock into the future. This issue is important to people who associate inflation persistence with a world in which monetary policy has real effects. It is important to us because inflation is highly persistent in postwar U.S. data. Fuhrer and Moore (1995) characterize inflation persistence in U.S. data using a vector autocorrelation function relating inflation and deviations of output from trend. In the vector autocorrelation function both inflation and output are highly persistent and there are significant positive cross-correlations between inflation and output.

This paper shows that a flexible-price, general-equilibrium business cycle model with an interest rate rule can account for these patterns. Based on Gavin and Kydland (1999), this real business cycle model has a shopping time specification for money and a central bank that follows a Taylor rule in making monetary policy. The only source of persistence is in the 
technology shock. There are no sticky prices and no liquidity effects. Agents' decisions in a period are taken only after all shocks are observed. The monetary policy rule transforms the output persistence into inflation persistence and creates a positive cross-correlation between inflation and output.

Of course, vector autocorrelation functions, themselves, do not provide evidence about a particular economic structure, but these time series facts are often invoked to justify the assumption that systematic monetary policy actions have real effects. The identification problem is difficult and there is no widely accepted solution. Nevertheless, we show that the inflation persistence can be caused by the central bank's interest rate policy, even in flexible price models.

The belief that prices are rigid has caused economists to discourage policymakers from policies that would provide price stability. Indeed, the conventional wisdom now uses the term price stability to mean stable inflation at a low rate. Yet, as we show in this paper, interest rate policies can cause inflation to be persistent and are likely to produce macroeconomic data that can be misinterpreted as supporting price rigidities. In our judgment, the persistence of inflation in fiat money systems is mainly a function of the monetary policy regime. There is an irony in using evidence created by poorly anchored monetary standards to justify policies that continue to produce uncertainty about the long-term price level.

In the next section we review some features of U.S. data. We then briefly describe the structure of our model. In the following sections, we use the model to show that inflation persistence and the observed cross-correlation function between inflation and output can be

\footnotetext{
${ }^{1}$ Although he does not stress this result, Dotsey (1999) shows that the Taylor rule produces inflation persistence in a model with sticky prices.
} 
caused by central banks using a version of the Taylor rule, even in the absence of nominal rigidities.

\section{U.S. DATA}

We begin by looking at U.S. data. Figure 1 shows the time series of inflation, the output gap, and the interest rate. Output is measured as per capita non-farm business sector output. The output gap is the deviation of output from a log-linear time trend. Inflation is defined as the change in the logarithm of the deflator for non-farm business sector output. The interest rate is the rate on the three-month Treasury yield. Both inflation and interest rates are shown as annualized rates.

In Figure 2, we reproduce the output and inflation components of a vector autocorrelation function similar to the one used by Fuhrer and Moore (1995) to illustrate some basic characteristics of U.S. data. Our time period is longer, but the shapes are almost identical to theirs. ${ }^{2}$ We also present one-standard-deviation bands around the estimated vector autocorrelation functions; the bands are constructed using the bootstrap technique described by Runkle (1987). The standard deviations are calculated from a distribution created with 10,000 draws from the randomized residuals.

As in Fuhrer and Moore (1995), this vector autocorrelation function is calculated from an unrestricted vector autoregression (VAR) in three variables: inflation, output, and the threemonth Treasury bill rate. Four lags of each variable were included. ${ }^{\text {The data and }}$ transformations are the same as those used by Fuhrer and Moore (1995). Starting in the upper-

\footnotetext{
${ }^{2}$ Gavin and Kydland $(1999,2000)$ show that the covariance structure of the nominal and real time series are not stable across the October 1979 policy change. We can also reject stability of the VAR across this breakpoint using a test proposed by Sims (1980), but our goal here is to replicate the work by Fuhrer and Moore.
} 
left-hand corner of Figure 2 and moving right, we see that inflation is highly persistent and at least one standard deviation above zero out to the tenth lagged quarter. The cross-correlations between inflation and the lagged output gap are positive and at least one standard deviation above zero out to 15 quarters. In the bottom-left-hand panel, the cross-correlations between output and the lagged inflation rate are negative, but not significantly different from zero except contemporaneously. Finally, the autocorrelation function for output gap shows that the output gap is also significantly persistent--with about the same autocorrelation function as for inflation. In the model we present below, the interest rate rule transforms the fundamental persistence in the output series into inflation persistence.

\section{THE ECONOMIC MODEL}

We investigate the effects of alternative monetary policy rules embedded in a neoclassical growth model with shocks to production technology, shopping time technology and the monetary policy rule. Allowing for stochastic money demand is important when we portray monetary policy in terms of money supply rules. Here the central bank uses an interest rate rule aimed at stabilizing output and controlling inflation. Thus, the shopping time specification matters only for the determination of the money stock; it is not important for the evolution of either prices or output. We include a stochastic shopping time technology so that we will have three independent sources of error in the data sets generated by our model. We begin with a brief overview of the model and then describe the monetary policy rule.

In each period of our model, the infinitely lived representative consumer decides how to allocate time between work and leisure. Larger money balances increase the amount of time that

\footnotetext{
${ }^{3}$ Note that Fuhrer and Moore included only three lags of the interest rate. We included four lags of all three variables.
} 
can be allocated to these two activities. Money enters the economy as a government transfer. The government sets a target for the nominal interest rate and transfers whatever amount of money is necessary to achieve the nominal interest rate target.

\section{The Economy}

Many identical households inhabit the model economy. Each household maximizes

$$
E \sum_{t=0}^{\infty} \beta^{t} u\left(c_{t}, \ell_{t}\right)
$$

where $0<\beta<1$ is a discount factor, $c_{t}$ is consumption expenditure, and $\ell_{t}$ is leisure time. The functional form of the current-period utility function is

$$
u\left(c_{t}, \ell_{t}\right)=\frac{1}{1-\gamma}\left[c_{t}^{\mu} \ell_{t}^{1-\mu}\right]^{1-\gamma}
$$

where $0<\mu<1$ and $\gamma>0$ but different from 1. This CES function, with unitary substitution elasticity between consumption and leisure, was chosen because it is consistent with postwar U.S. data in which long-run hours worked per person remain roughly constant despite the large increase in real hourly compensation.

The household's stock of capital, $k$, is governed by the law of motion,

$$
k_{t+1}=(1-\delta) k_{t}+x_{t},
$$

where $0<\delta<1, \delta$ is the depreciation rate, and $x_{t}$ is investment.

The representative agent spends available time, $T$, in three basic activities: input in market production, leisure, and transaction-related activities such as trips to the bank, shopping, and so on. Larger money balances make the shopping activity less time consuming. By holding 
more money, households have more time for work and/or leisure. Household time spent on transactions-related activities in period $t$ is given by

$$
\omega_{0}-\Omega_{t}\left(\frac{m_{t}}{P_{t} c_{t}}\right)^{\omega_{2}}
$$

where

$$
\Omega_{t}=\bar{\Omega}+\sqrt{|\bar{\Omega}|} \varepsilon_{t}^{d},
$$

$m_{t}$ is the nominal stock of money, and $P_{t}$ is the price of physical goods relative to that of money.

Shopping time technology, $\Omega_{t}$, is equal to its steady state level plus an innovation, $\varepsilon_{t}^{d}$, that is independent and identically distributed with a zero mean and variance, $\sigma_{d}^{2}$. The shock is scaled by the square root of the steady state level of the shopping time technology so that the error itself is scaled in the monetary unit. By restricting $\Omega_{t}$ and $\omega_{2}$ to have the same sign and $\omega_{2}<1$, the amount of time saved increases as a function of real money holdings in relation to consumption expenditures, but at a decreasing rate.

Leisure in period $t$ is

$$
\ell_{t}=T-n_{t}-\omega_{0}+\Omega_{t}\left(\frac{m_{t}}{P_{t} c_{t}}\right)^{\omega_{2}}
$$

where $T$ is the total time available and $n_{t}$ is time spent in market production.

The budget constraint for the typical individual is

$$
c_{t}+x_{t}+\frac{m_{t+1}}{P_{t}}=w_{t} n_{t}+r_{t} k_{t}+\frac{m_{t}+v_{t}}{P_{t}}
$$


where $w_{t}$ is the real wage rate, $\mathrm{r}_{t}$ is the real interest rate, and $v_{t}$ is a nominal lump-sum transfer from the government.

Aggregate output, $Y_{t}$, is produced using labor and capital inputs:

$$
Y_{t}=C_{t}+X_{t}=z_{t} N_{t}^{\theta} K_{t}^{1-\theta},
$$

where $X_{t}$ is the total of investment expenditures and $z_{t}$ is the level of technology that is subject to transitory shocks. The technology changes over time according to

$$
z_{t+1}=(1-\rho) \bar{z}+\rho z_{t}+\lambda_{t+1},
$$

where $0<\rho<1$ and the innovation, $\lambda_{t+1}$, is distributed with a zero mean and with variance $\sigma_{\lambda}^{2}$. The steady state level of technology, $\bar{z}$, is set equal to 1 .

A law of motion analogous to that for individual capital describes the aggregate quantity of capital. The distinction between individual and aggregate variables is represented here by lowercase and uppercase letters, respectively. This distinction plays a role when computing the equilibrium of a model with government policy in which the equilibrium is not simply the solution to a stand-in planner's problem. Competitive factor markets will imply that in equilibrium each factor receives its marginal product. Therefore, in equilibrium we have both:

$$
w_{t}=\theta\left(\frac{K_{t}}{N_{t}}\right)^{1-\theta}
$$

and:

$$
r_{t}=(1-\theta)\left(\frac{K_{t}}{N_{t}}\right)^{-\theta}
$$




\section{Monetary Policy}

We have used the model described above in other work, and we have refrained from adding investment in nominal bonds to avoid complicating the discussion of it. We note that a nominal investment in capital in the amount $P_{t-1} k_{t}$ made at time $t-1$, will have a nominal value of $P_{t}\left(r_{t} k_{t}+(1-\delta) k_{t}\right)$ at time $t$. The implied gross nominal return to capital investment, therefore, is given by:

$$
\left(1+R_{t}\right)=\frac{P_{t}}{P_{t-1}}\left(r_{t}+1-\delta\right)
$$

If nominal government bonds paying a gross nominal return of $\left(1+R_{t}\right)$ were introduced in the agent's budget constraint and assumed to be in zero net supply, the above condition would result as an equilibrium condition. While the central bank has no direct control over the real rate in this economy, it can control the economy's nominal rate by means of the above equilibrium condition by using an appropriate monetary transfer.

Since the early 1960s, the Federal Reserve has used an indicator of reserve market pressures to guide open market operations. For most of the time since the 1970s, that indicator is the interest rate on bank reserves, the federal funds rate. By setting a short-term target for the federal funds rate, the Fed automatically supplies reserves to meet unexpected shocks to money demand. We assume that the central bank uses this control over the monetary transfer to implement the following modified version of the interest rate rule proposed by Taylor (1993):

$$
R_{t+1}=\bar{r}+\bar{\pi}+v_{y}\left(\ln Y_{t}-\ln \bar{Y}\right)+v_{\pi}\left(\pi_{t}-\bar{\pi}\right)+\varepsilon_{t+1}^{s},
$$

where $R_{t+1}$ is the period $t+1$ nominal interest rate target chosen by the central bank in period $t$; $\pi_{t}=\ln P_{t}-\ln P_{t-1}$ is the inflation rate; the bar over a symbol refers to the steady state value; and 
there is also a policy shock, $\varepsilon_{t}^{s}$, that is independent and identically distributed with a zero mean and variance, $\sigma_{s}^{2}$.

\section{First-Order Conditions}

Due to the constraints on the agent's choices, his choice of any three variables - say leisure, consumption, and investment - will determine the others via his budget and time constraints. Therefore, there are only three unique first-order conditions that can be derived from the agent's optimizing behavior. Roughly, the first can be considered as arising from the choice between leisure and consumption. We will write this intratemporal optimality condition as:

$$
\frac{\partial u}{\partial l}\left(c_{t}, l_{t}\right)\left(1-w_{t} \Omega_{t} \omega_{2}\left(\frac{m_{t}}{P_{t} c_{t}}\right)^{\omega_{2}} \frac{1}{c_{t}}\right)=w_{t} \frac{\partial u}{\partial c}\left(c_{t}, l_{t}\right) .
$$

This expression is complicated by the fact that the agent's time spent at leisure is dependent on his time spent shopping, which in turn depends on consumption. In the absence of shopping time, this condition takes the better known form,

$$
\frac{\frac{\partial u}{\partial l}\left(c_{t}, l_{t}\right)}{\frac{\partial u}{\partial c}\left(c_{t}, l_{t}\right)}=w_{t}
$$

which is the standard condition equating of the ratio of marginal utilities of leisure and consumption to the real wage rate.

In this model there are two ways of substituting consumption across time. One is through investment in capital, and the other is through holding money. If we define

$$
\kappa_{t}=1-w_{t} \Omega_{t} \omega_{2}\left(\frac{m_{t}}{P_{t} c_{t}}\right)^{\omega_{2}} \frac{1}{c_{t}}
$$

then the first of these intertemporal substitution conditions is: 


$$
\frac{\partial u}{\partial c}\left(c_{t}, l_{t}\right)=\beta E_{t}\left[\frac{\kappa_{t}}{\kappa_{t+1}} \frac{\partial u}{\partial c}\left(c_{t+1}, l_{t+1}\right)\left(r_{t+1}+1-\delta\right)\right] .
$$

Again note that in the absence of shopping time, this first-order condition becomes the familiar expression,

$$
\frac{\partial u}{\partial c}\left(c_{t}, l_{t}\right)=\beta E_{t}\left[\frac{\partial u}{\partial c}\left(c_{t+1}, l_{t+1}\right)\left(r_{t+1}+1-\delta\right)\right]
$$

which equates the ratio of expected marginal utilities to the gross real interest rate.

Finally, we have the first-order condition associated with the choice of money balances.

It can be written as:

$$
\frac{\partial u}{\partial c}\left(c_{t}, l_{t}\right)=\beta E_{t}\left[\frac{\kappa_{t}}{\kappa_{t+1}} \frac{P_{t}}{P_{t+1}}\left(1+\frac{P_{t+1} c_{t+1}}{m_{t+1}}\left(\kappa_{t+1}-1\right)\right) \frac{\partial u}{\partial c}\left(c_{t+1}, l_{t+1}\right)\right] .
$$

Written in this way, we can see that if there are no shopping time costs, then $\kappa_{t}=1$ for all $t$ and the above condition reduces to:

$$
\frac{\partial u}{\partial c}\left(c_{t}, l_{t}\right)=\beta E_{t}\left[\frac{P_{t}}{P_{t+1}} \frac{\partial u}{\partial c}\left(c_{t+1}, l_{t+1}\right)\right]
$$

Again, this is a standard equilibrium condition for money or any asset held in equilibrium. The ratio of expected marginal utilities is equal to the expected real return on that asset. In the case of money the return is the inverse of the inflation rate or $P_{t} / P_{t+1}$. 


\section{Calibration}

The model is calibrated using empirical estimates of steady-state relations among the model's variables and parameters. Most of the estimates come from long-run or average values. Measurements from panel data also are used. The parameter $\theta$ in the production function equals the model's steady-state labor share of output and is set equal to 0.65 . This is in line with estimates obtained for the United States if approximately half of proprietors' income is considered to be labor income. We use a quarterly depreciation rate of 0.025 .

Turning to the household sector, the annual real interest rate is 4 percent, yielding a quarterly discount factor, $\beta$, of approximately 0.99 . The risk-aversion parameter, $\gamma$, is set equal to 2 , which means more curvature on the utility function than that corresponding to logarithmic utility. This value is consistent with the empirical findings of Neely, Roy, and Whiteman (1999).

We calibrate the money-time tradeoff so that the implied money demand function is consistent with the empirical evidence summarized by Lucas (1994) and Mulligan and SaliMartin (1997). The money demand relationship in the model has a unitary elasticity of the scale variable (consumption). When we set $\omega_{2}$ (the curvature parameter in the money-time trade-off) equal to -1 , the interest rate elasticity equals -0.5 .

With the steady state output and money stock normalized to unity, the steady-state price level is determined by setting the annual income velocity of money at 5.8-approximately equal to the average of M1 velocity between 1959 and 1994 . Given the price level, we derive $\Omega$ from the household's first-order condition for the choice of money holding:

$$
\Omega=\frac{r}{\omega_{2} w} c^{\omega_{2}}\left(\frac{m}{P}\right)^{1-\omega_{2}},
$$


where the real wage rate, $w$, equals the steady state marginal product of labor, and $r$ is the quarterly real interest rate. The implied steady-state value of $\Omega$ is -0.0034 . The magnitudes of $\Omega$ and $\omega_{2}$ can be understood through a marginal evaluation around the average. If the real money stock is increased by 1 percent relative to its steady state, then a household's resulting weekly time saving is less than a minute.

Without loss of generality, we choose time units so that $n+\ell=1$. In line with the panel-data estimates of Ghez and Becker (1975), we set $n$ so that $n /(n+\ell)=0.3$. The remaining parameter $\mu$, the share of consumption in the utility function, usually is determined from the condition $M U_{\ell} / M U_{c}=w$ and usually turns out to be close to $n$ in magnitude. In this case, because of the dependence of time (and therefore $\ell$ ) on $m / P c$, the corresponding condition can be written as

$$
\frac{u_{1}}{u_{2}}=\frac{\ell}{w}+\frac{\Omega \omega_{2}}{c}\left(\frac{m}{P c}\right)^{\omega_{2}} .
$$

The implied value for $\mu$ is 0.33 . Unless otherwise noted, the parameters in the Taylor rule, $v_{\pi}$ and $v_{y}$, are set equal to 0.5 .

\section{Dynamic Competitive Equilibrium}

We compute the dynamic competitive equilibrium for this model by using the recursive method outlined in Kydland (1989) and Hansen and Prescott (1995). To solve the model, we first determine the model's steady state analytically and then take a quadratic approximation to the agent's utility function around this point. We use the agent's budget constraints to eliminate some variables from the problem and write the agent's utility as a function solely of variables 
grouped as exogenous state variables, $s_{1, t} ;$ endogenous state variables, $s_{2, t} ;$ aggregate state variables, $S_{t}$; decision variables, $d_{t}$; and economy-wide variables, $D_{t}$. The set of exogenous state variables includes the production and shopping time technology parameters. It also includes the natural logarithm of the gross nominal interest rate and the one-period lag of the natural logarithm of the price level. The complete list of the exogenous variables is as follows:

$$
S_{1, t}=\left(1, z_{t}, \Omega_{t}, \ln \left(P_{t-1}\right), \ln \left(R_{t}\right)\right)^{\prime} .
$$

A constant is included in this formulation to make the Taylor series approximation to the utility function a quadratic form in the above listed variables. The other variables in the agent's problems are chosen as:

$$
\begin{gathered}
s_{2, t}=\left(\ln \left(k_{t}\right), \ln \left(m_{t}\right)\right)^{\prime} \\
S_{t}=\left(\ln \left(K_{t}\right), \ln \left(M_{t}\right)\right)^{\prime} \\
d_{t}=\left(\ln \left(y_{t}\right), \ln \left(k_{t+1}\right), \ln \left(m_{t+1}\right)\right)^{\prime}, \text { and } \\
D_{t}=\left(\ln \left(Y_{t}\right), \ln \left(K_{t+1}\right), \ln \left(M_{t+1}\right)\right)^{\prime} .
\end{gathered}
$$

State variables at time $t+1$ are expressed as linear functions of time $t$ variables as follows:

$$
\left(\begin{array}{c}
s_{1, t+1} \\
s_{2, t+1} \\
S_{t+1}
\end{array}\right)=A_{1} S_{1, t}+A_{2} S_{2, t}+A_{3} S_{t}+A_{4} d_{t}+A_{5} D_{t} .
$$

With a quadratic approximation to the utility function and linear transition equations for the state variables, the Bellman equation for the agent,

$$
V\left(s_{1, t}, s_{2, t}, S_{t}\right)=\operatorname{Max}_{d_{t}} E_{t}\left[U\left(s_{1, t}, s_{2, t}, S_{t}, d_{t}, D_{t}\right)+\beta V\left(s_{1, t+1}, s_{2, t+1}, S_{t+1}\right)\right],
$$

has as its solution a quadratic form in the variables $s_{1, t}, s_{2, t}$ and $S_{t}$. Furthermore, the decision rules that solve this problem are linear in $s_{1, t}, s_{2, t}, S_{t}$, and $D_{t}$. Rules determining economy-wide variables are found by imposing consistency conditions. When the individual endogenous 
variables are identified with their aggregate counterparts, the individual decision variables must also be consistent with their aggregate counterparts. Individual output, capital, and money decisions must match their economy-wide counterparts. Note that this identification implicitly determines the level of money that the central bank must supply to implement its Taylor rule.

\section{MONETARY POLICY IN A REAL BUSINESS CYCLE MODEL}

In this section, we conduct several experiments to see how alternative monetary policy rules will affect the behavior of output and inflation. Table 1 summarizes the default calibration assumptions that were used in the experiments. Information about deviations from this baseline case is listed in the figures when appropriate. In this flexible price model, prices adjust rapidly to shocks. Before looking at the results using an interest rate rule, we will briefly review what happens in the simple case where the central bank's monetary policy takes the form of a rule for the money supply. If we add money through a one-time transfer to households, the price level, inflation, and the nominal interest rate will jump immediately. The price level will tend to remain at the higher level. In the next period, inflation and the nominal interest rate return to their original values. Because real money balances reduce shopping time, an increase in inflation will cause a slight decline in output, but the decline is trivially small in the scale of business cycle fluctuations.

If the money stock is fixed, a technology shock will cause output to rise and to gradually return to its steady state path. The responses of output, the price level, inflation, and the interest rate to a technology shock when the money supply is fixed are shown in Figure 3. The price level, inflation, and the nominal interest rate will decline by less than the amount of the output shock because the falling interest rate causes an increase in the demand for money by 
households. The nominal interest rate returns to the steady state level in the period following the technology shock. Inflation remains slightly negative and the real interest rate remains slightly positive for several years.

Next, in Figure 4, we show the vector autocorrelation function that is generated by data from this model when the money supply is equal to a constant plus a random shock. To construct these functions we follow the method used by Fuhrer and Moore (1995). That is, we run a VAR in three variables generated by the model: the percentage deviation of output from the steady state, the deviation of inflation from the steady state target, and the nominal interest rate. We generate 100 VARs from draws of shocks to the three stochastic elements in the model. Throughout the experiments run in this study, the processes for output and/or inflation are close to being nonstationary and sometimes the VAR has unstable roots. In those cases we throw out the result and draw again. In each figure showing a vector autocorrelation function, we have a note indicating the number of runs thrown out, if any. As shown in Figure 4, when the money supply is set equal to a constant plus a random error, there is no persistence in inflation and only small and negative cross-correlations between inflation and output. ${ }^{1}$ Of course, there is persistence in output induced by persistence in the technology shock.

Next we examine the response of the economy to technology and monetary policy shocks when the central bank is following a Taylor-type rule. In a real business cycle model with flexible prices and no liquidity effects, the central bank will destabilize inflation if it reacts too strongly to an increase in the deviation of inflation from target. The price level is undetermined for values of $v_{\pi}$ greater than unity.

\footnotetext{
${ }^{4}$ Adding a persistent monetary transfer does not change these results. Most of the price adjustment occurs in the period of the shock, so inflation is not persistent even though monetary growth is.
} 
Note that this result stands is sharp contrast to the conclusion of Clarida, Gali, and Gertler (2000), in which the price level is not determined if $v_{\pi}$ is less than unity. The difference lies in the monetary transmission mechanism. In our model, the channel is through inflation expectations. The steady state target is credible, and the interest rate target is achieved by choosing the current-period inflation rate so that changes in the expected real interest rate are offset by changes in the expected inflation rate. In the United States, the Fed acts daily to add or drain monetary reserves to keep the overnight interest rate near its target. Fed officials observe neither the daily expected real rate nor the daily expected inflation rate. Much of the controversy over how monetary policy works can be reduced to disagreement about whether daily open market operations mainly affect the expected real interest rate or the expected inflation rate components. In Clarida, Gali, and Gertler $(1999,2000)$, the focus is on the Fed's ability to control the expected real interest rate. In our model, the channel is through the Fed's control over the expected inflation rate.

Figure 5 shows the impulse response of the economy to a positive technology shock when the central bank is following a Taylor rule. The shock is scaled to be one standard deviation of the steady state level of technology. Because the technology level is highly persistent, output stays above its steady state value for a long time. Because there is a positive gap between output and its steady state level, following the Taylor rule leads the central bank to hold the interest rate above its steady state rate. There is a very small increase in the real interest rate, so that the rise in the nominal rate mainly reflects a rise in the expected inflation rate. Both the nominal interest rate and inflation gradually return to their steady state values as the effects of the technology shock on output decay. The result of the slow decay is a slow increase in the price level that peaks in 52 quarters, 18.7 percent above the steady state. Innovations in 
technology cause inflation and output to be positively correlated because, by following the Taylor rule, the central bank acts to raise nominal interest rates by more than the increase in real interest rates.

A policy shock is defined as an increase in the nominal interest rate of 25 basis points. Figure 6 shows the impulse responses of output, the price level, inflation, and the interest rate to a policy shock. The policy shock has only a trivial negative effect on output. The price level rises by about 25 basis points in the period of the shock and peaks at less than $1 / 2$ percent above the steady state in period six. The 25 basis point increase in the interest rate is almost entirely an increase in the expected inflation rate. Inflation rises 24.5 basis points in period one and half of that in the next period as the central bank implements the Taylor Rule. The real interest rate rises slightly as the higher inflation reduces real money balances and causes a shift of time away from work and toward shopping. This effect, only 0.3 basis points, is trivial and is not discernable in Figure 6. The interest rate and the inflation rate appear to lie on the same line.

Figure 7 shows the vector autocorrelation function that occurs with a Taylor rule. Here, the vector autocorrelation function shows that inflation is highly persistent. Furthermore, the cross-correlations between inflation and output are very high and persistent, more than is evident in the data.

\section{SENSITIVITY TESTS}

In preparing for this study, we thought that interest rate smoothing would be important. Dotsey (1999) uses a model with sticky prices to show that the output effects of a monetary policy shock are greatly amplified with interest rate smoothing. He also found that inflation persistence may disappear if the central bank smoothes interest rates. In our flexible price 
model, the most important effect we found was that interest rate smoothing tends to dampen the initial policy response to technology shocks but makes the effect last longer. However, the autocorrelations functions that we estimated are not very sensitive to the degree of interest rate smoothing. Mainly, the effect was to moderate the high cross-correlations that we found between output and inflation.

Clearly the results depend on having an autocorrelated output gap. Otherwise, the results for the output and inflation vector autocorrelations are relatively insensitive to the calibration of the real business cycle model. We found almost no change in the shape of the vector autocorrelations for a range of reasonable values of the relative risk-aversion parameter (we checked values from 1.5 to 5), the labor/capital share in production (0.55 to 0.65$)$, or the steady state interest rate (from 1.5 to 7.5 percent). The results are relatively insensitive to changes in the shopping time parameters. Often, it has been noted that analysts who use the Taylor rule in their models ignore money. As McCallum (2000) notes, the only role for money demand in these models is to determine the path of the money supply. As a practical matter, both in the real world and in our models, money demand doesn't matter if the central bank is using an interest rate target to guide open market operations. Changes in factors affecting the demand for money will not affect the paths of either inflation or output. Of course, the case is very different if the central bank is targeting the money supply (even if it is only one of several variables in the central bank's objective function). Then the dynamics of inflation will be affected by factors that affect the demand for money.

When using a Taylor rule, we found that the results are not very sensitive to changes in the weight on inflation. Using a feedback rule for the money supply that included past values of the money supply and output, Gavin and Kydland (1999) show that changes in the relative 
weight on output can cause large changes in the output-inflation correlations. In the Taylor Rule used here, that is also true; reducing the weight on output makes a big difference. Figure 8 shows how the correlations change when we lower $v_{y}$ to .05 . Here the shape is somewhat closer to the data. If we put no weight on output, setting $v_{y}$ to 0 , we find that the cross correlations become negative. In our model, the positive correlation between inflation and the output gap that is typically considered evidence of a Phillips Curve is strictly an artifact of the policy rule.

\section{CYCLICAL BEHAVIOR OF INFLATION AND THE PRICE LEVEL}

In our flexible price model, alternative monetary policy rules have little effect on the real variables. Real Business Cycle (RBC) models with exogenous money supply rules typically generate countercyclical behavior of the price level. Gavin and Kydland (1999) showed that the sign and size of the output-price correlation depends on whether and how output enters the reaction function for the money supply rule. One anomaly found in that paper was that the price level and the inflation rate correlations invariably have the same sign because the cycles, although opposite in sign, are synchronized. This is also the case in the flexible-price models presented in Cooley and Hansen (1995). In the data, the price level is negatively correlated with output and the inflation rate is positively correlated because the price level tends to lead output by two to four quarters. In the sticky price model presented by Cooley and Hansen, the signs were opposite, but this was due to a phase shift in the wrong direction. There, the trough in the price level lags the output cycle by a quarter.

Modeling central bank policy as a rule for the interest rate accounts for that anomaly. Table 2 shows the cyclical behavior of nominal variables with correlations calculated from U.S. data, as well as correlations calculated from our model with the Taylor rule. In this case we 
follow the standard in the RBC literature and detrend the data with the Hodrick-Prescott (HP) filter before computing the business cycle correlations. Here we use results from Gavin and Kydland (2000). Output is measured as business sector output. The price level is measured as the chain price index for personal consumption expenditures. Inflation is measured as the change in the natural logarithm of this price index.

As Table 2 shows, the model matches two key features of the data. First, the price index is negatively correlated with output and the trough leads output by 3 to 4 quarters. Second, inflation is positively correlated with output. The biggest discrepancy is in the volatility of the

price level and inflation. Both the price level and inflation generated by the model are about four times more volatile (as measured by the percent standard deviation from a HP trend) than we see in the data. Finally, in the last two rows we show the cyclical behavior of the one-period nominal interest rate. We used the yield on the three-month Treasury bill rate to measure the one-period nominal interest rate. As we saw in the impulse response functions in Figures 5 and 6 , variability in the model's nominal interest rate is driven by variability in inflation. This is consistent with the similarity of the cyclical behavior of inflation and the three-month Treasury bill rate in U.S. data.

\section{CONCLUSION}

Inflation persistence has been considered evidence against flexible price rational expectation models because it is nearly impossible to generate inflation persistence in these models if the central bank is following an autoregressive money supply rule. Most of the work in these models was done using such money supply rules. We show that it is quite easy to generate inflation persistence in flexible price models if the central bank is following an interest 
rate rule of the type suggested by Taylor (1993). The reason is simply that the central bank influences inflation directly when it targets an interest rate.

The empirical regularities represented by the autocorrelation functions in this paper-the high positive correlations between inflation and output—are broadly interpreted as evidence that monetary policy has large real effects. We generate such autocorrelations in a flexible price RBC model with no liquidity effects and no other frictions except a small transaction cost for purchasing consumption.

Methodologically, our results illustrate the danger in using priors about the size and shape of econometrically identified impulse response functions to restrict specification searches in business cycle models. One should not be required to match theoretical impulse response functions to econometric estimates. In our opinion, one should not be restricted to models that display large real effects of monetary policy. Rather, the more modest requirement should be to find models that are able to generate data with time-series properties similar to those of data collected by the statistical agencies. 


\section{References}

Ball, Laurence. " Credible Disinflation with Staggered Price-Setting," American Economic Review, Vol. 84, No. 1 (March 1994), pp. 282-289.

Clarida, Richard, Jordi Gali, and Mark Gertler, "Monetary Policy Rules and Macroeconomic Stability: Evidence and Some Theory," Quarterly Journal of Economics, (February 2000), pp.147-180.

$\underset{\text { Perspective," }}{\text {, Journal of Economic Literature, December 1999, 37:4, 1661-707. }}$

Cooley, Thomas F., and G.D. Hansen. "Money and the Business Cycle," in Frontiers of Business Cycle Research, Thomas F. Cooley, ed., Princeton University Press, 1995, pp. 175-216.

Dotsey, Michael. "The Importance of Systematic Policy for Economic Activity," Federal Reserve Bank of Richmond Economic Quarterly, Vol. 85, No. 3 (Summer 1999), pp. 41-59.

Fuhrer, Jeffrey C., and George R. Moore. "Inflation Persistence," Quarterly Journal of Economics, February 1995, 110(1), pp. 127-159.

Gavin, William T., and Finn E. Kydland. "Nominal Facts and the October 1979 Policy Change," Federal Reserve Bank of St. Louis Review (November/December 2000), pp. 3961.

, and _ _Endogenous Money Supply and the Business Cycle," Review of Economic Dynamics Vol. 2, No. 2 (1999), pp. 347-369

Ghez, Gilbert R. and Gary S. Becker. The Allocation of Time and Goods over the Life Cycle. New York: Columbia University Press, 1975.

Hansen, Gary D., and Edward C. Prescott. "Recursive Methods for Computing Equilibria of Business Cycle Models," in Frontiers of Business Cycle Research, T.F. Cooley, ed., pp. 39-64, Princeton University Press, Princeton, 1995.

Kydland, Finn E. "Monetary Policy in Models with Capital," in Dynamic Policy Games in Economic, F. van der Ploeg and A. J. de Zeeuw, eds., pp. 267-288, North-Holland, Amsterdam, 1989.

Lucas, Robert E. Jr., "Inflation and Welfare," Econometrica, March 2000, Vol. 68, No. 2, pp. $247-74$. 
McCallum, Bennett T. "Conducting Monetary Policy without Reference to Monetary Aggregates," Review, Federal Reserve Bank of St. Louis, Forthcoming July/August 2000.

Mulligan, Casey B., and Xavier X. Sali-Martin. "The Optimum Quantity of Money: Theory and Evidence." Journal of Money, Credit, and Banking, Part 2 November 1997, Vol. 29, No. 4, pp. 687-715.

Neely, Chris, Amlan Roy, and Charles Whiteman. "Identification Failure in the Intertemporal Consumption CAPM," Federal Reserve Bank of St. Louis, Working Paper 95-002C, Revised June 1999. Forthcoming in The Journal of Business and Economic Statistics.

Runkle, David E. "Vector Autoregressions and Reality," Journal of Business and Economic Statistics (October 1987), pp. 437-442.

Sims, Christopher. "Macroeconomics and Reality," Econometrica, 1980.

Taylor John B. "Discretion versus Policy Rules in Practice," Carnegie-Rochester Conference Series on Public Policy, December 1993, 39, 195-214. 
Table 1: Parameter Calibration for the Baseline Case

\section{Parameter}

Depreciation rate

Steady state real interest rate

Discount factor

Relative risk aversion

Consumption share in utility

Shopping time parameters

Labor share in production

Steady state share of time

supplying labor services

Fed's reaction to inflation

Fed's reaction to output gap

Persistence in the

Technology shock

\section{Standard deviation of}

\section{Shocks}

Production Technology

Payments technology

Monetary policy

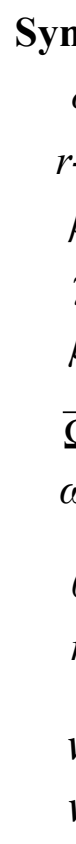

$\begin{array}{cc}\text { mbol } & \text { Value } \\ \delta & 0.025 \\ r-\delta & (1.04)^{\wedge} 0.25-1 \\ \beta & 1 /(1+r-\delta) \\ \gamma & 2 \\ \mu & 0.33\end{array}$

$\bar{\Omega}$

$-0.00345$

$-1$

0.65

0.3

0.5

0.5

$\rho$

0.95

$\sigma_{z}$

0.0075

$\sigma_{d}$

0.0015

$\sigma_{s}$

0.25 
Table 2: Cyclical Behavior of the Price Level, Inflation and the Nominal Interest Rate (with baseline calibration)

\begin{tabular}{|c|c|c|c|c|c|c|c|c|c|c|c|c|}
\hline \multirow[b]{2}{*}{ variable } & \multicolumn{12}{|c|}{ Cross-Correlation of Output with } \\
\hline & $\mathrm{SD} \%$ & $x(t-5)$ & $x(t-4)$ & $x(t-3)$ & $x(t-2)$ & $\mathrm{x}(\mathrm{t}-1)$ & $x(t)$ & $\mathrm{x}(\mathrm{t}+1)$ & $x(t+2)$ & $x(t+3)$ & $x(t+4)$ & $x(t+5)$ \\
\hline \multicolumn{13}{|c|}{ Price Level } \\
\hline Model & 4.63 & -0.55 & -0.58 & -0.58 & -0.55 & -0.47 & -0.32 & -0.10 & 0.12 & 0.30 & 0.43 & 0.51 \\
\hline Data & 0.89 & -0.65 & -0.67 & -0.65 & -0.62 & -0.56 & -0.46 & -0.36 & -0.28 & -0.22 & -0.13 & -0.07 \\
\hline \multicolumn{13}{|c|}{ Inflation } \\
\hline Model & 1.12 & -0.21 & -0.12 & -0.01 & 0.14 & 0.33 & 0.58 & 0.88 & 0.87 & 0.72 & 0.53 & 0.34 \\
\hline Data & 0.28 & -0.12 & 0.00 & 0.13 & 0.18 & 0.22 & 0.35 & 0.33 & 0.26 & 0.25 & 0.32 & 0.20 \\
\hline \multicolumn{13}{|c|}{ Nominal Interest Rate } \\
\hline Model & 1.14 & -0.20 & -0.11 & 0.01 & 0.16 & 0.36 & 0.61 & 0.89 & 0.87 & 0.71 & 0.52 & 0.33 \\
\hline Data & 1.09 & -0.49 & -0.27 & -0.11 & 0.16 & 0.43 & 0.56 & 0.55 & 0.46 & 0.35 & 0.26 & 0.13 \\
\hline
\end{tabular}

Notes: The results for U.S. data come from Gavin and Kydland (2000). For this table, the price level and inflation were measured using the chain price index for personal consumption expenditures (PCE). The correlations were computed for data spanning the period from 1979:Q4 to 1998:Q4. The interest rate was taken to be the yield on three-month Treasury bills for the period from 1982:Q4 to 1998:Q4. Output was defined as business sector output. See Gavin and Kydland (2000) for a more complete description of the cyclical behavior of nominal time series in the United States since 1959. 
Figure 1: U.S. Data for Output, Inflation and the Interest Rate
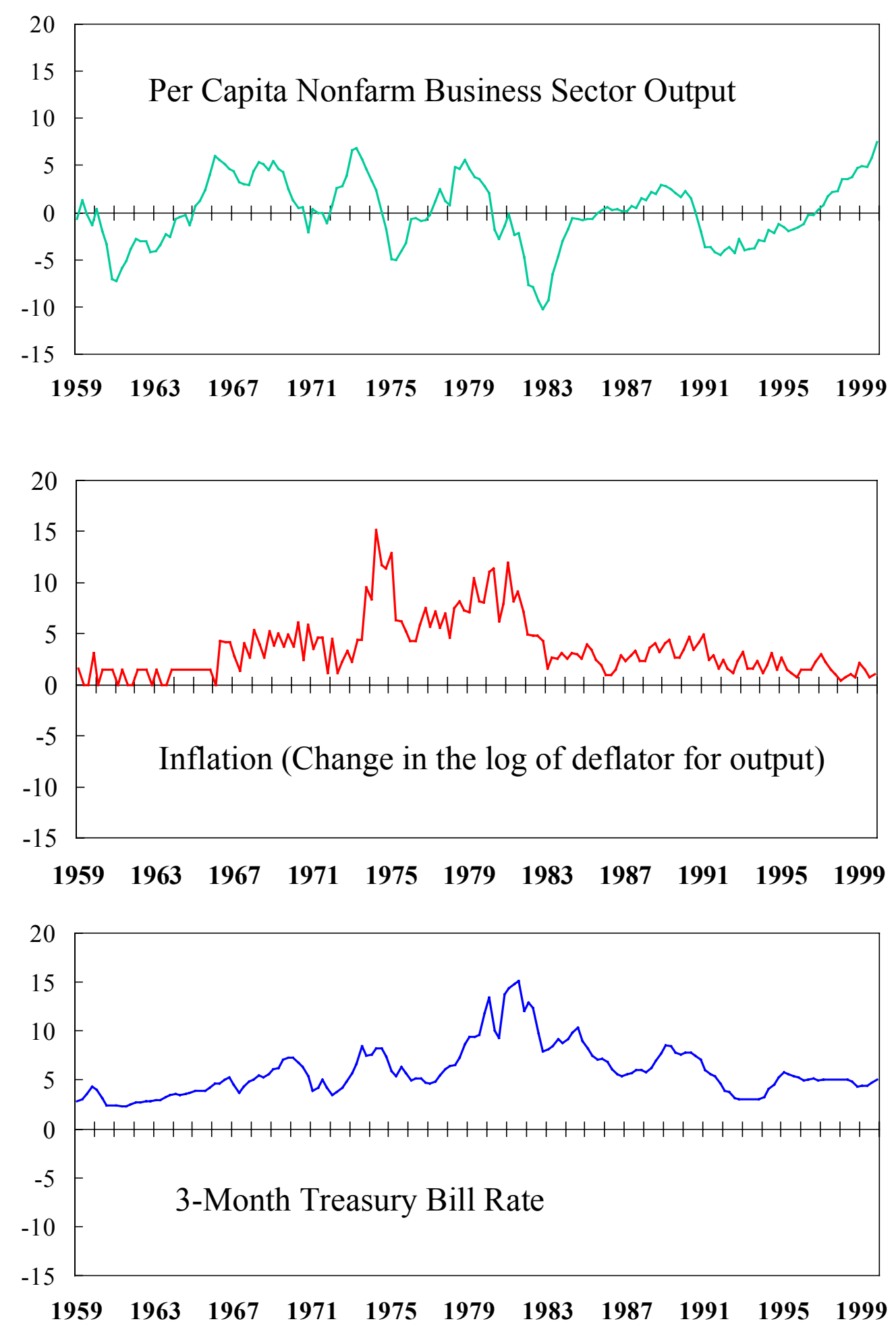
Figure 2: U.S. Data Vector Autocorrelation Function

1959:Q1 to 1999:Q4
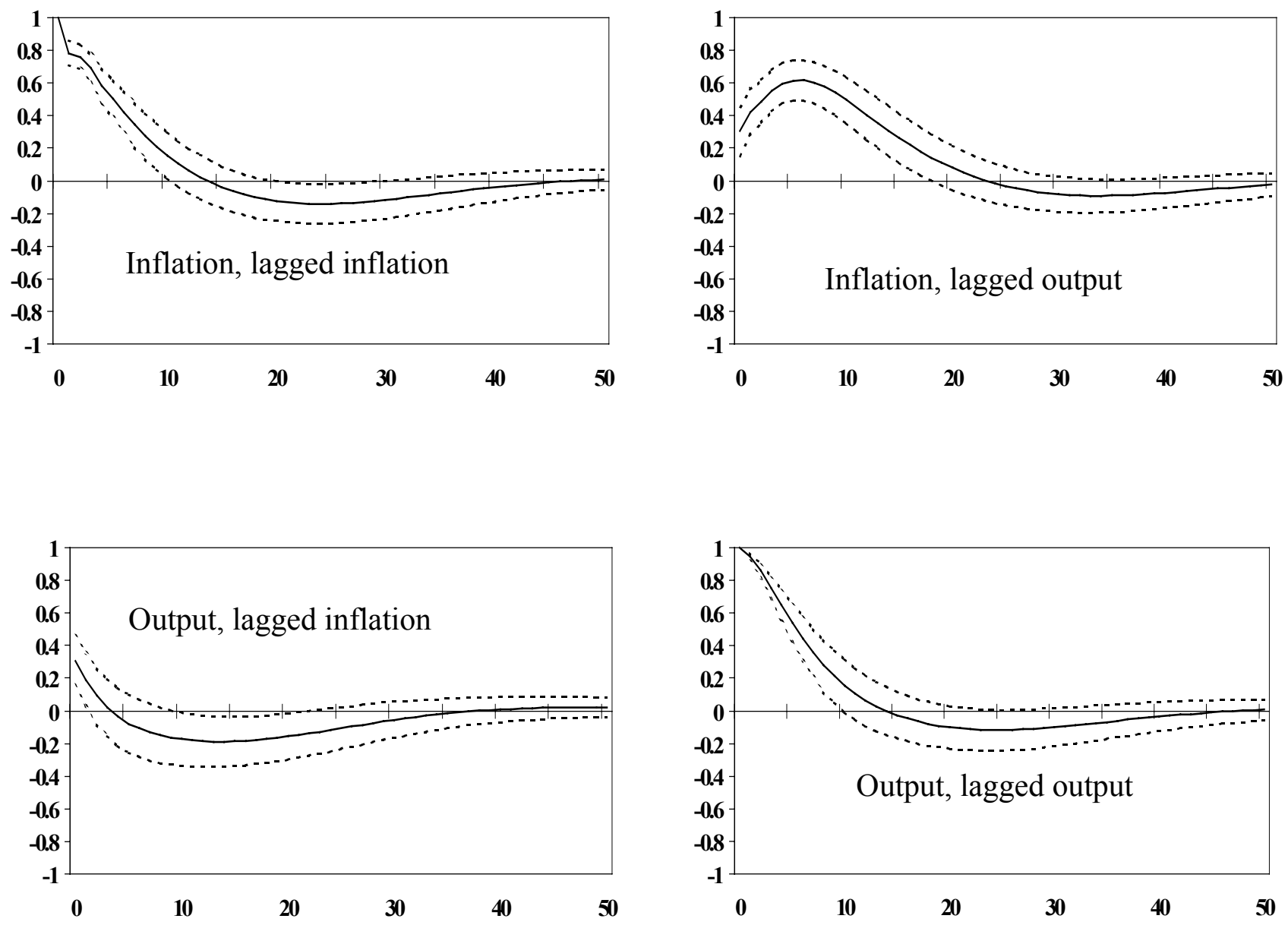

One-standard deviation error bands are calculated using a bootstrap method with 10,000 draws. 
Figure 3: Impule Responses to a Technology Shock with a Fixed Money Stock
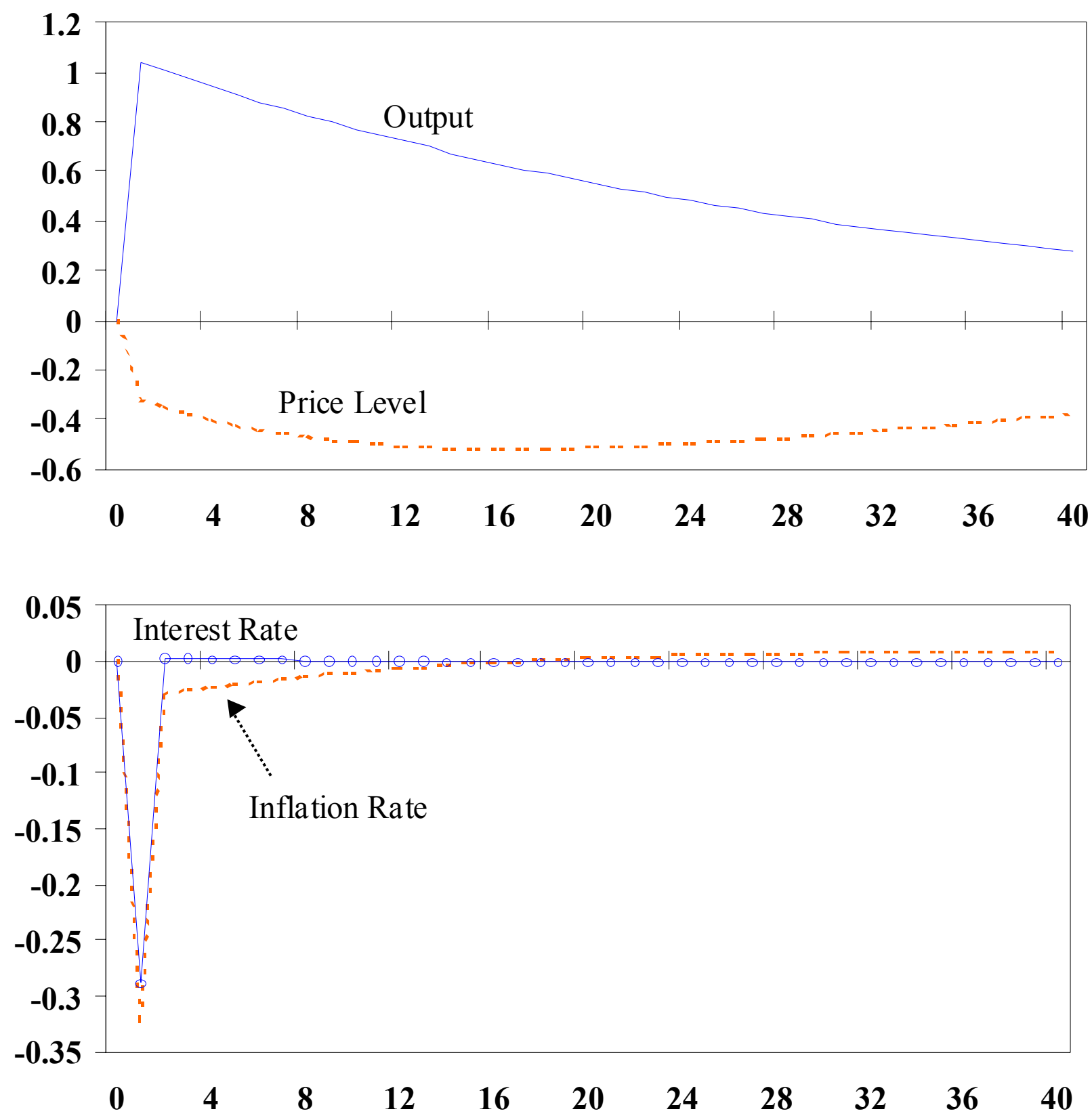

Interest rates are shown in percentage points. Other variables are scaled as percentage deviations from the steady state value. 
Figure 4: Vector Autocorrelation Function Using Model Data with a Fixed Money Stock

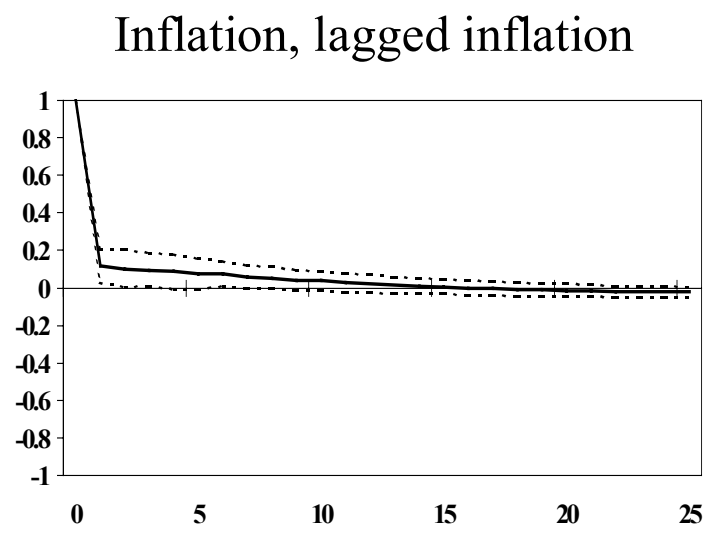

Output, lagged inflation

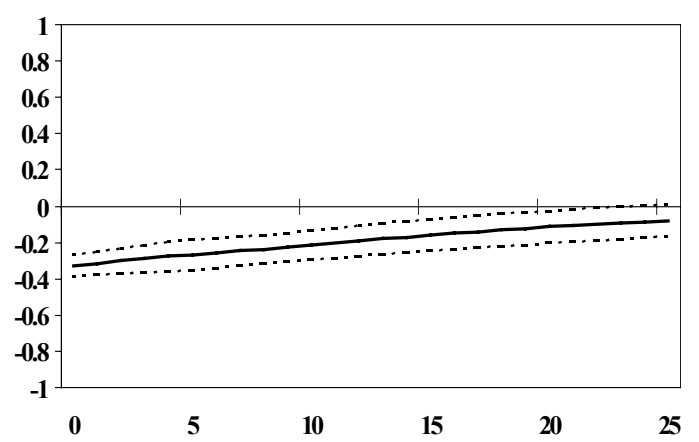

Inflation, lagged output

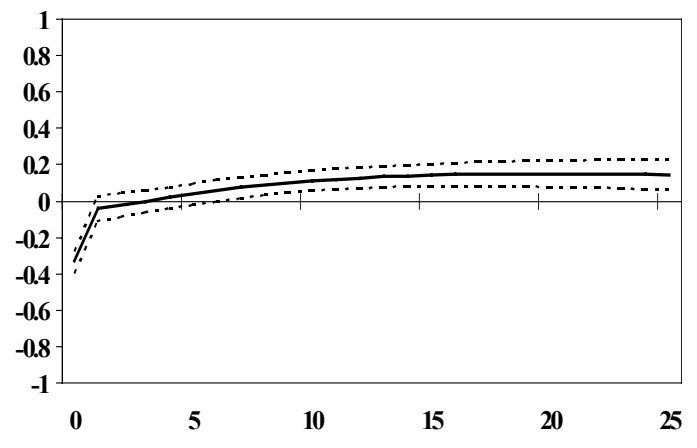

Output, lagged output

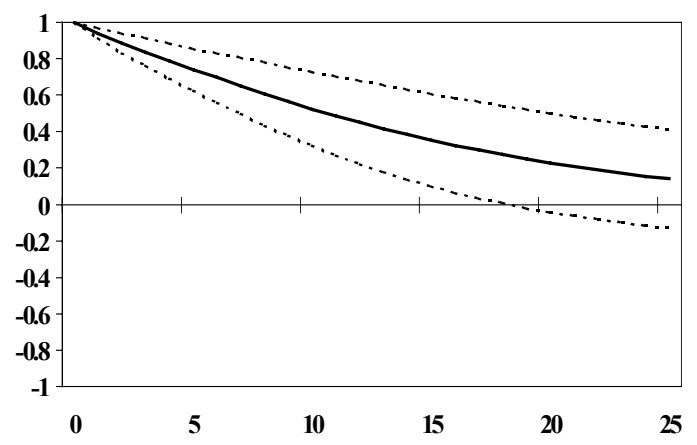

These are the average vector autocorrelation functions computed from 100 histories. The dashed lines reflect plus and minus one standard deviation. 
Figure 5: Impulse Responses to a Technology Shock with a Taylor Rule (The technology shock raises output one percent above the steady state)
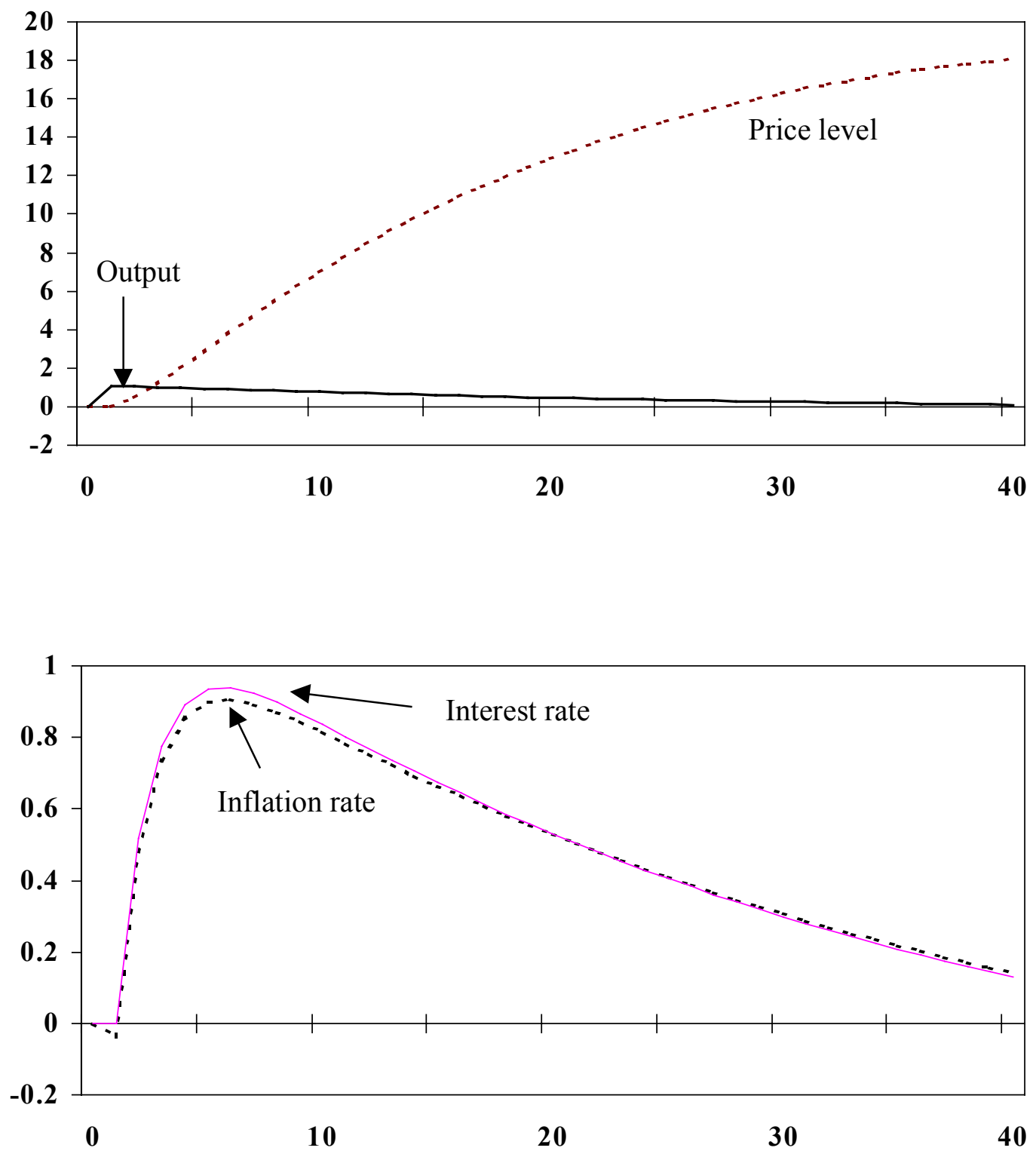

Interest rates shown in percentage points. Other variables are scaled as percentage point deviations from the steady state. 
Figure 6: Impulse Responses to a Policy Shock with a Taylor Rule (The policy shock raises the interest rate by 25 basis points)
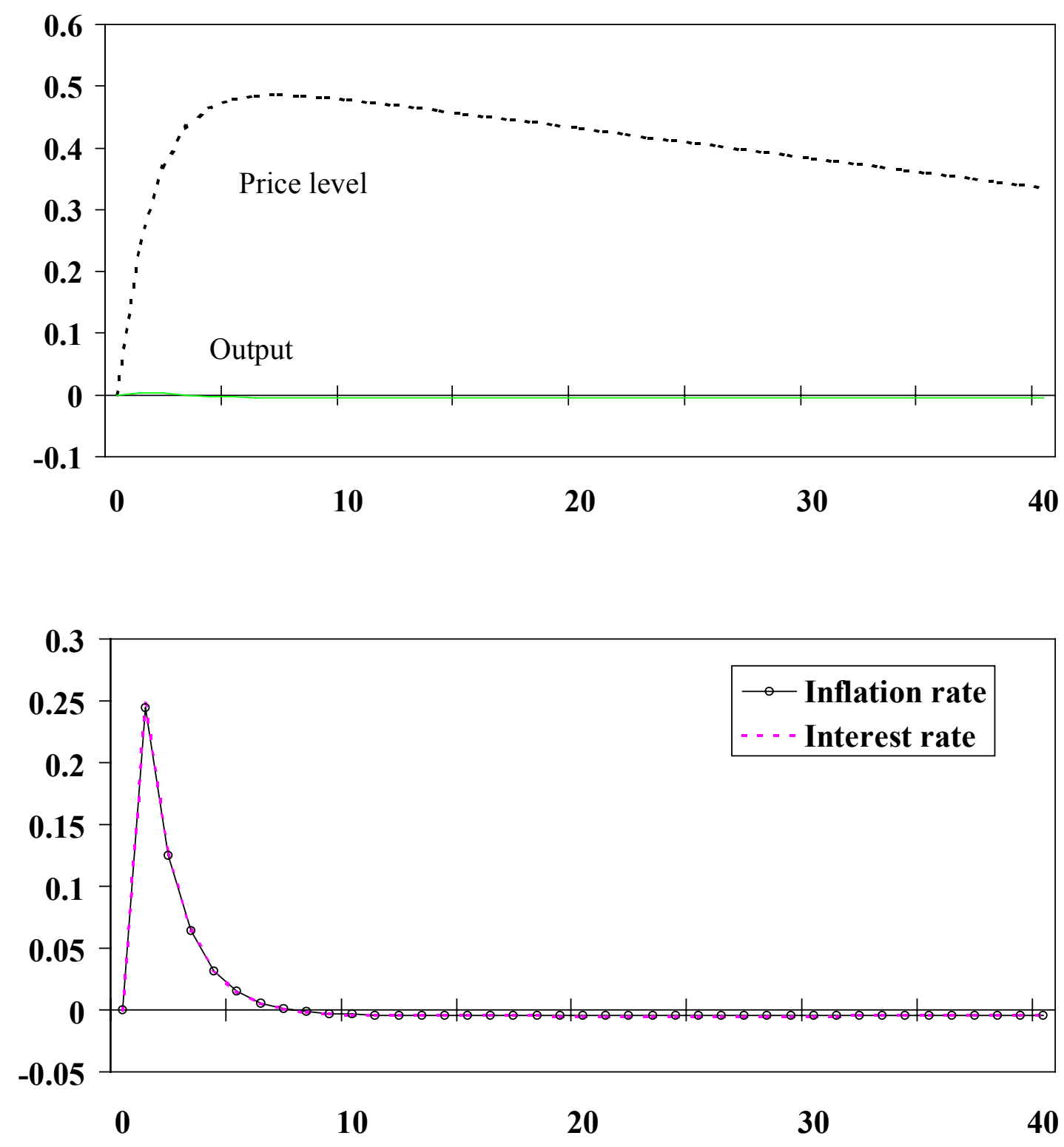

Interest rates shown in percentage points. Other variables are scaled as percentage point deviations from the steady state. 
Figure 7: Vector Autocorrelation Function Using Model Data with a Taylor Rule
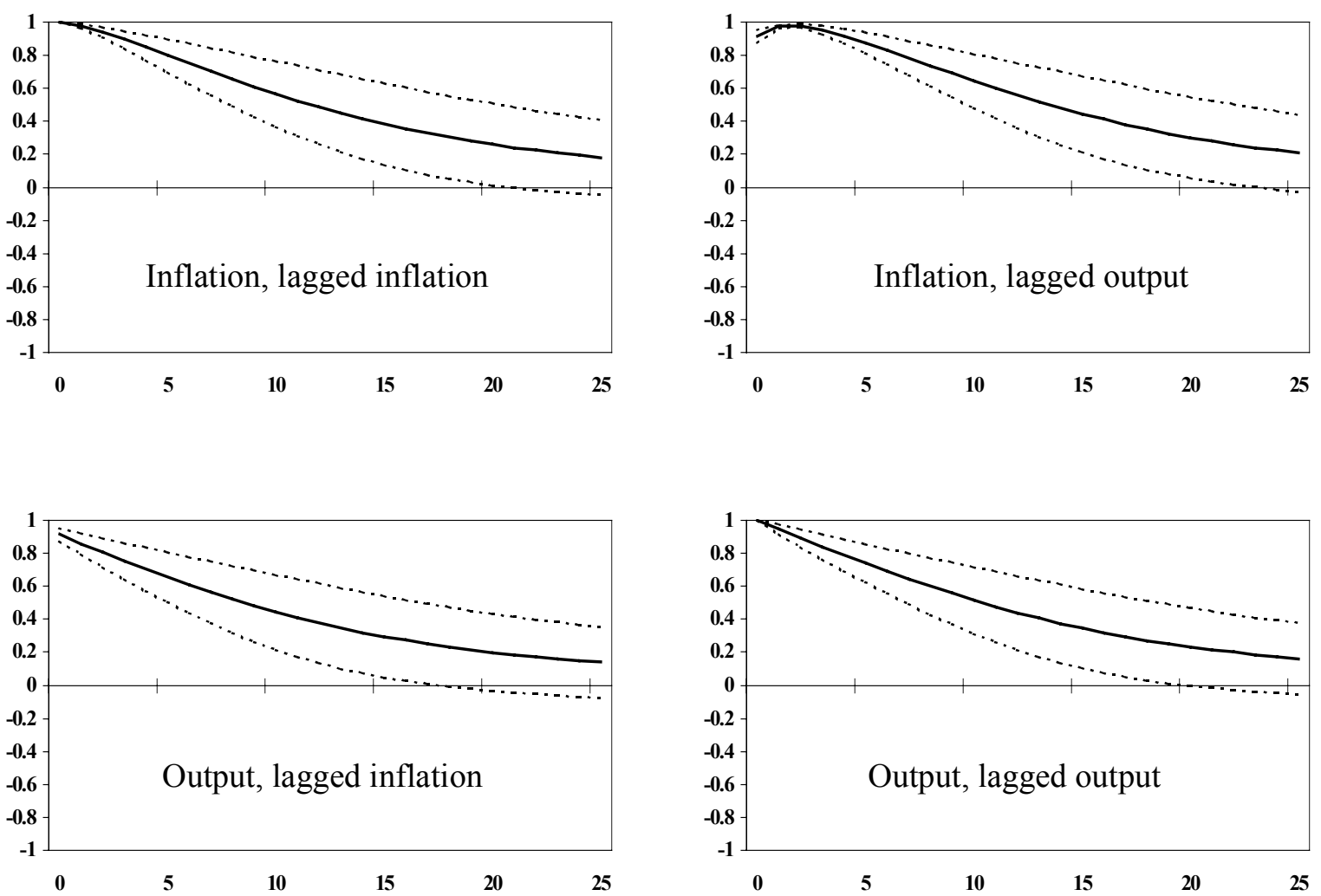

These are the average vector autocorrelation functions computed from 100 histories. The dashed lines reflect plus and minus one standard deviation. Two draws were rejected because the roots of the VAR were unstable. 
Figure 8: Vector Autocorrelation Function Using Model Data with Little Weight on Output $\left(v_{\pi}=0.5\right.$ and $\left.v_{y}=0.05\right)$
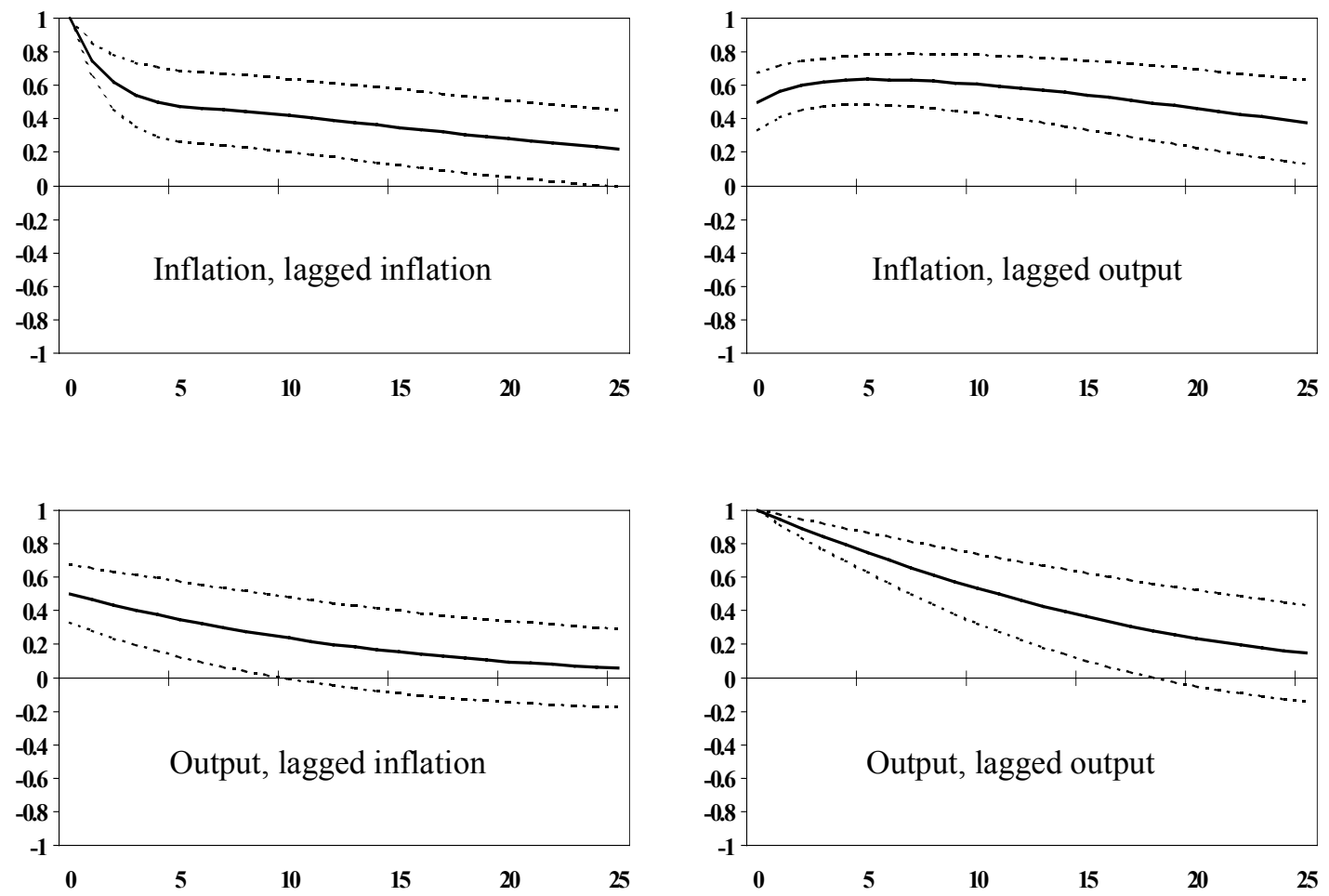

These are the average vector autocorrelation functions computed from 100 histories. The dashed lines reflect plus and minus one standard deviation. 


\section{Figure 9: Vector Autocorrelation Function Using Model Data with No Weight}

on Output $\left(v_{\pi}=0.5\right.$ and $\left.v_{y}=0\right)$
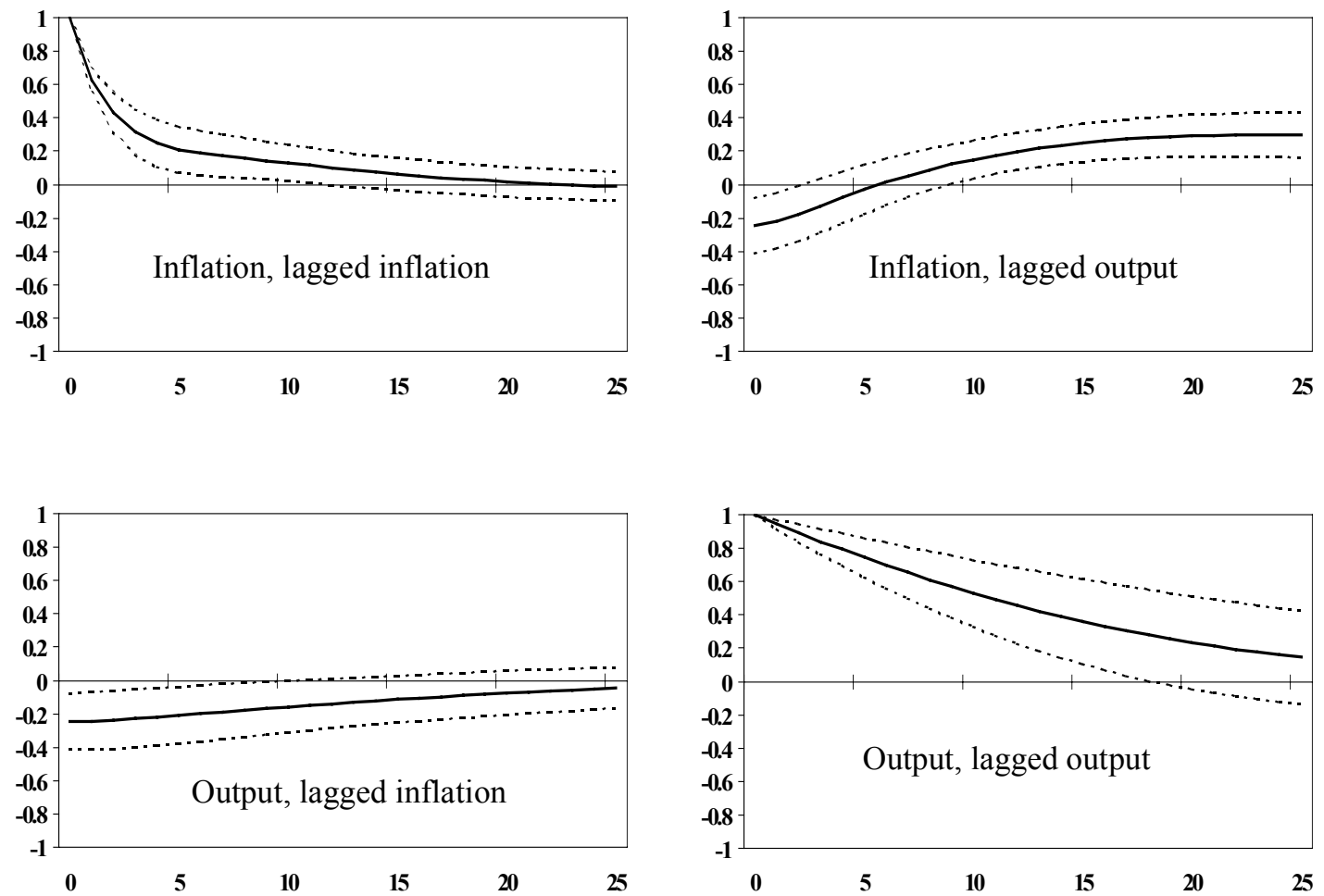

These are the average vector autocorrelation functions computed from 100 histories.

The dashed lines reflect plus and minus one standard deviation. 